\title{
Cardiac function after surgery for subaortic stenosis: non-invasive assessment of left ventricular performance
}

Department of

Paediatric Cardiology, Royal Brompton National Heart and Lung Hospital, London

K-Y Chan

A N Redington

M L Rigby

Department of

Cardiology, Royal

Brompton National

Heart and Lung

Hospital, London

D G Gibson

Correspondence to

Dr Andrew N Redington, Department of Paediatric Cardiology, Royal Brompton

National Heart and Lung Hospital, Sydney Street, London SW3 6NP.

Accepted for publication 24 January 1991

Kit-Yee Chan, Andrew N Redington, Michael L Rigby, Derek G Gibson

Abstract

Objective-To examine left ventricular function after surgical resection of subaortic stenosis during childhood.

Design-Left ventricular performance was measured non-invasively in all patients who responded to an invitation for formal assessment.

Setting-Outpatient study, tertiary referral centre.

Patients-Twenty three (12 male and 11 female) patients (age range 3 to 31 years) of 43 consecutive patients with fixed subaortic stenosis undergoing surgical resection between 1975 and 1989 reattended for formal assessment 16 months to 15 years (median 4 years 4 months) after operation.

Main outcome measures-Left ventricular dimension, left ventricular wall thickness, left ventricular Doppler inflow velocities, and left ventricular diastolic pressure (measured from apexcardiograms). Results were compared with those in controls individually matched for age and sex.

Results-All patients were symptom free. Left ventricular cavity dimensions were normal, as was the mean fractional shortening. Posterior wall thickness tended to be greater in the patients and there was a significant increase in septal thickness. Normalised peak rate of posterior wall thinning was significantly lower in the patients and the isovolumic relaxation time was significantly shorter. Doppler inflow velocity measurements showed that early diastolic mitral flow acceleration time was normal but deceleration time was significantly shorter in the patients. The ratio of mitral flow in early diastole (E) to $E$ plus mitral flow in late diastole (A) was significantly higher in the patients and in two patients there was complete absence of $A$ wave flow despite large $A$ waves on the apexcardiogram.

Conclusions-Systolic function was well preserved in patients after operation for subaortic stenosis. A restrictive pattern of left ventricular filling was common, however, and presumably reflected a response to the chronic pressure load and to surgery in the paediatric heart.
Fixed subvalvar aortic stenosis accounts for 8$10 \%$ of all left ventricular outflow tract obstructive lesions. Associated mitral and aortic valve structural abnormalities are not uncommon $^{1}$ and the incidence of aortic incompetence is also high..$^{2-4}$ Early surgical removal is usually associated with good relief of the obstruction ${ }^{56}$ but asymptomatic recurrence is well described. ${ }^{178}$ Because of the high incidence of residual morphological and functional abnormalities we examined ventricular systolic and diastolic function in patients who had had resection for subaortic stenosis.

\section{Patients and methods}

PATIENTS

We studied patients in whom there was fixed subvalvar stenosis caused by either a thin fibrous shelf or a thick fibrous ridge demonstrated by echocardiography or angiography and confirmed at operation. We excluded patients with other forms of subvalvar obstruction.

From 1975 to 1989,43 consecutive patients (aged 8 months to 24 years (median 9 years 8 months)) underwent surgical resection of fixed subaortic stenosis. Eleven foreign patients were lost to follow up and were excluded from the study. The remaining 32 were recalled for a formal evaluation. Of the 24 patients who responded, 23 (12 male, 11 female) had data suitable for analysis. The ages at the time of assessment ranged from 3 to 31 years (median 14 years 8 months). The follow up period ranged from 16 months to 15 years 6 months (median 4 years 4 months) from the time of the second operation.

There were two patients with von-Recklinghausen disease - one with hemi-vertebrae and severe kyphoscoliosis-and one had William's syndrome. One patient had left atrial isomerism with absence of the inferior vena cava and a left superior vena cava draining into the coronary sinus. Other cardiovascular abnormalities were found in 11 patients. A ventricular septal defect was present in six (small and restrictive perimembranous (four), subaortic (one), large and doubly committed subarterial (one). There were four patients with coarctation; three had had repair to the aorta in infancy before the subsequent operation for resection of subaortic stenosis. Cross sectional echocardio- 
graphy showed an abnormal aortic valve in seven patients; three with bicuspid valves and four with three thickened leaflets. Significant right ventricular outflow tract obstruction caused by muscle bundles in the right ventricle was found in two patients. Preoperative cardiac catheterisation was performed in 21 patients. The left ventricular-aortic peak to peak gradient ranged from 20 to $105 \mathrm{~mm} \mathrm{Hg}$ (56 (29) $\mathrm{mm} \mathrm{Hg}$ ). Aortography showed trivial aortic regurgitation in two.

The subaortic ridge was excised in all patients. Six required additional myectomy of the adjacent interventricular septum.

All six patients with ventricular septal defects had the lesions closed, five at the same operation and one eight years before the operation for subaortic stenosis. Right ventricular muscle bundles were resected in two patients: one had a ligation of a ductus arteriosus and another had coarctation repair during the same operation. At the time of operation, thickening of the aortic valve leaflets was found in four but this was not severe enough to warrant valvotomy. Four patients required a second operation because of recurrence five to 14 years after the initial resection.

All patients had a full clinical examination, 12 lead electrocardiogram, and chest radiograph. Data were also obtained individually on age (in months) and sex matched healthy controls. Controls were not matched for body surface area.

\section{Methods}

CROSS SECTIONAL DOPPLER ECHOCARDIOGRAPHY AND APEXCARDIOGRAMS

Resting cross sectional, $M$ mode, and pulsed wave Doppler echocardiography with simultaneous electrocardiography and phonocardiography was performed with a HewlettPackard Sonos 1000 ultrasound system. The phonocardiogram was recorded over the point on the chest at which residual murmurs were best heard, usually at the upper left sternal edge. $M$ mode echocardiograms of mitral and aortic valve motion and of the left ventricular cavity just below the level of the free edges of the mitral valve leaflets were recorded. Mitral Doppler flow velocity was measured in the pulsed mode from apical four chamber views with the sample volume placed between the tips of valve leaflets where the maximum flow velocity in early diastole was measured. Continuous wave Doppler was used to assess the pressure gradients across the left ventricular outflow tract by the modified Bernoulli equation. Measurements were made at rest and wherever possible at submaximal exercise. All $M$ mode and Doppler recordings were made with a Honeywell (Ecoline 22) strip chart recorder at a paper speed of $100 \mathrm{~mm} / \mathrm{s}$.

Apexcardiograms were recorded from the point of maximum impulse over the left ventricular apex by a Cambridge transducer with a time constant of four seconds. ${ }^{9-11}$ Recordings were made with the patient in a left lateral decubitus position unless satisfactory recordings could be obtained in the supine position and they were usually recorded at the end of normal expiration.

\section{ANALYSIS}

Digitisation of left ventricular $M$ mode

echocardiograms

Only recordings in which septal and left ventricular posterior wall echoes could be clearly identified for at least three entire cardiac cycles were digitised. Echocardiograms were digitised as previously described, ${ }^{12-14}$ by tracing echoes from both sides of the ventricular septum and from the endocardial and epicardial surfaces of the left ventricular posterior wall. From the digitised data of three averaged beats we made plots of the septal and posterior wall echoes and measured the following features: $(a)$ left ventricular dimension with measurement of the rate of change of dimension as a function of time; (b) fractional shortening; (c) peak rate of dimension increase during early diastole; and $(d)$ peak rate of left ventricular posterior wall thinning.

The rate of change of dimension and wall thickness were also normalised by dividing its value by the instantaneous dimension so as to adjust for physiological variations in ventricular size, wall thickness, and systolic function. The normalisation factors improve the clinical usefulness of the indices, ${ }^{12}{ }^{13}$ especially in children where age and size vary widely.

\section{$M$ mode and Doppler echocardiography}

Peak mitral flow velocity in early diastole (E wave) and with atrial contraction (A wave) were measured and expressed as either $E / A$ or the ratio $\mathrm{E} / \mathrm{E}+\mathrm{A} .{ }^{15}{ }^{16}$ Early diastolic mitral flow acceleration and deceleration time were also measured. ${ }^{1718}$ The left ventricular isovolumic relaxation period was measured as the interval from the aortic closure sound $\left(A_{2}\right.$ on phonocardiogram) to the opening of the mitral valve as assessed by cusp separation on the $M$ mode echocardiogram (18 patients) and to the onset of the flow velocity signal on the Doppler traces (15 patients). All measurements were calculated from a mean of three cardiac cycles.

\section{Apexcardiograms}

Total diastolic deflection ('A') and total vertical deflection $(\mathrm{O}-\mathrm{E})$ were measured; an $\mathrm{A} / \mathrm{O}-\mathrm{E}$ ratio $>33 \%$ suggested a high left ventricular filling pressure (fig 1).

\section{DATA ANALYSIS}

All data were expressed as mean (SD). The statistical significance of differences between group means was assessed by Student's $t$ test. The association between various indices of diastolic function was tested by linear correlation and multiple rank correlation coefficients.

\section{Results}

At the time of re-evaluation, one patient was in New York Heart Association class II-III. The remainder were symptom free, described their quality of life as good, and took part in full normal activities. Physical examination showed 


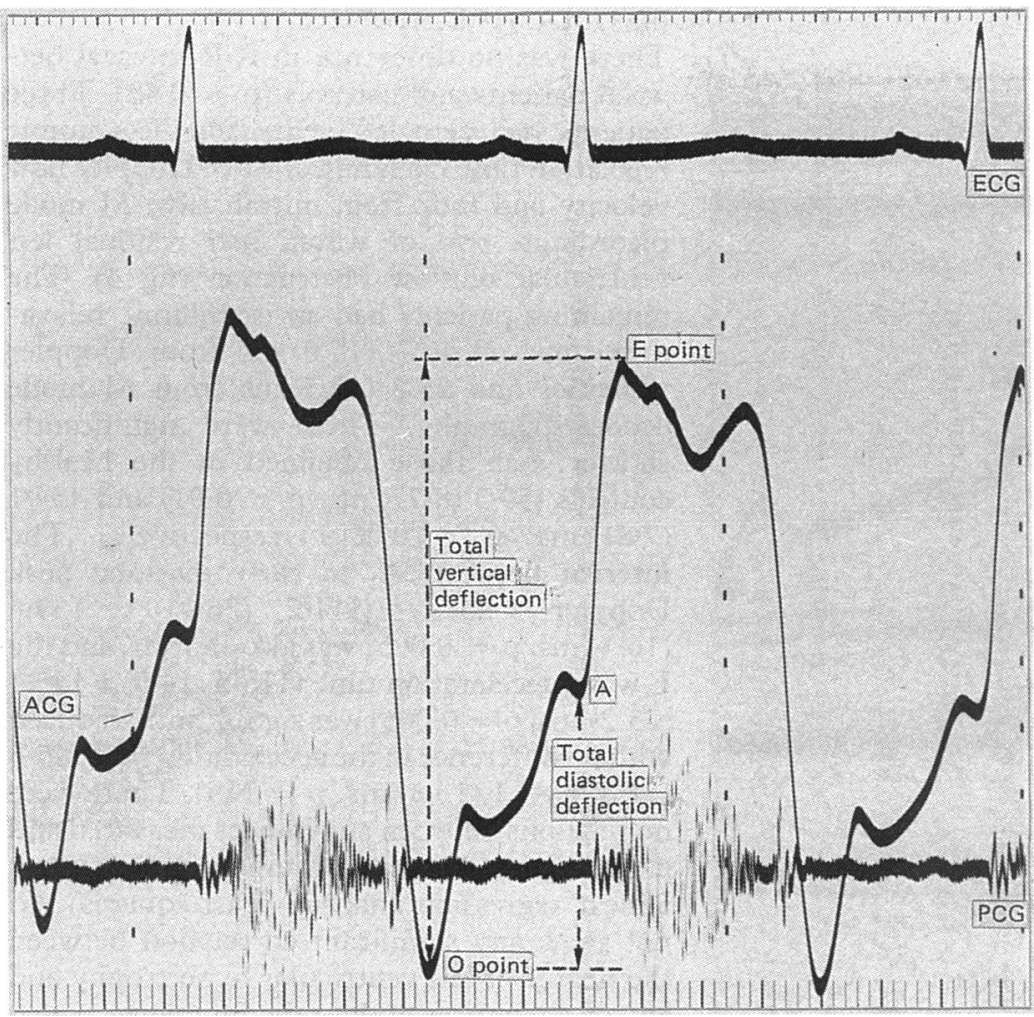

Figure 1 Apexcardiogram ( $A C G$ ) from a patient with moderate restenosis. Ratio of total diastolic deflection (' $A$ ') to total vertical deflection $(O-E)$ increased to $47 \%$, reflecting left ventricular diastolic disease. ECG, electrocardiogram; $P C G$, phonocardiogram. had moderate to severe obstruction with recurrence of a shelf lesion in three. Continuous wave Doppler gradients across the left ventricular outflow measured from the suprasternal notch were 52,64 , and $64 \mathrm{~mm} \mathrm{Hg}$ respectively, increasing to 108,81 , and $96 \mathrm{~mm} \mathrm{Hg}$ with exercise in these patients. One other patient had dynamic subaortic obstruction and left ventricular concentric hypertrophy with a Doppler gradient of $85 \mathrm{~mm} \mathrm{Hg}$. The mean systolic gradient in all patients was 21 (17) $\mathrm{mm} \mathrm{Hg}$. Mild aortic regurgitation was described by Doppler echocardiography in 13 with moderate regurgitation in one other patient.

LEFT VENTRICULAR CAVITY, SEPTAL, AND POSTERIOR WALL DYNAMICS

Mean cavity dimensions at end systole and end diastole were $27.9(0.7) \mathrm{mm}$ and $43.0(9.0) \mathrm{mm}$ respectively. Neither differed significantly from those in the healthy controls $(28.1(0.4)$ and $42.0(5.5) \mathrm{mm}$ respectively). The mean fractional shortening was $35.3(7 \cdot 6) \%$ in the subaortic stenosis group and $34.3(4.9) \%$ in the healthy controls ( $p=N S)$.

Septal thickness at end diastole was, however, significantly greater than in the healthy controls $(11.8(2.9) v 10.0(2.3) \mathrm{mm}, \mathrm{p}<0.05)$. The percentage systolic septal thickening was, however, not different $(29.4(10.4)$ v 27.5 $(9 \cdot 2) \%, p=N S)$. The septal thickness correlated with the left ventricular dimension at end systole $(r=0.41, p<0.05)$ and posterior wall thickness $(r=0.42, p=0.03)$. In the four patients with significant residual left ventricular outflow obstruction, the septal thickness ranged from 10 to $18 \mathrm{~mm}$ (mean $14.8 \mathrm{~mm}$ ).

The posterior wall thickness tended to be greater in the group with subaortic stenosis $(13.9(4.0) \mathrm{mm}) v 11.9(3.0) \mathrm{mm}, \mathrm{p}=0.07)$. The thickness ranged from 15 to $22 \mathrm{~mm}$ (mean $17.8 \mathrm{~mm}$ ) in the four patients with residual obstruction.

The normalised peak rate of posterior wall thinning was less in the study group (4.0 $(1 \cdot 6) \mathrm{s})$ than in the healthy controls $(5 \cdot 3(1 \cdot 1) \mathrm{s}$, $p=0.005)$. The normalised peak rate of increase of left ventricular dimension during diastole (patients $3.2(1 \cdot 1) v$ controls $3 \cdot 1+$ $0.8 \mathrm{~s}$ ) was not different. There were inverse correlations between the posterior wall thinning rate and posterior wall thickness $(p=$ $0.03)$ and left ventricular dimension $(p=0.03)$.

\section{CROSS SECTIONAL AND M MODE}

ECHOCARDIOGRAPHY

None of the patients with associated ventricular septal defects had residual shunts detectable with Doppler colour flow imaging. One patient with previous coarctation repair had a Doppler derived instantaneous gradient of $25 \mathrm{~mm} \mathrm{Hg}$ across the repair site. Abnormal insertion of the papillary muscles of the mitral valve was noted in three patients but the peak mitral valve flow velocity was within normal limits in all. None had mitral regurgitation.

There were nine patients with evidence of mild subaortic narrowing with turbulence detectable by colour flow imaging but no definite shelf and an insignificant Doppler gradient $(20 \mathrm{~mm} \mathrm{Hg})$ across the left ventricular outflow tract at rest and with exercise. Four patients

\section{APEXCARDIOGRAMS}

Apexcardiograms of adequate quality were recorded in 17 patients. Eight patients had a normal $\mathrm{A} / \mathrm{O}-\mathrm{E}$ ratio $(<33 \%)$. In the remaining nine the ratio ranged from $35 \%$ to $66 \%$ (mean $47 \%$ )(fig 1 ). The 'a' wave deflection was small in eight patients. These abnormalities were reflected in the mitral inflow Doppler recordings where both $E / A$ and $E / E+A$ were greater in $(0.13) v 0.64(0.03)$, respectively, both $\mathrm{p}<$ $0.05)$. Two patients with recurrence of subvalvar stenosis had absence of ' $A$ ' waves on Doppler flow studies. 'a' Waves were, however, echocardiograms of these patients (fig 2), sugthe patients $(2.14(0.63) v 1.79(0.24)$ and 0.73 present on the apexcardiograms and $M$ mode 


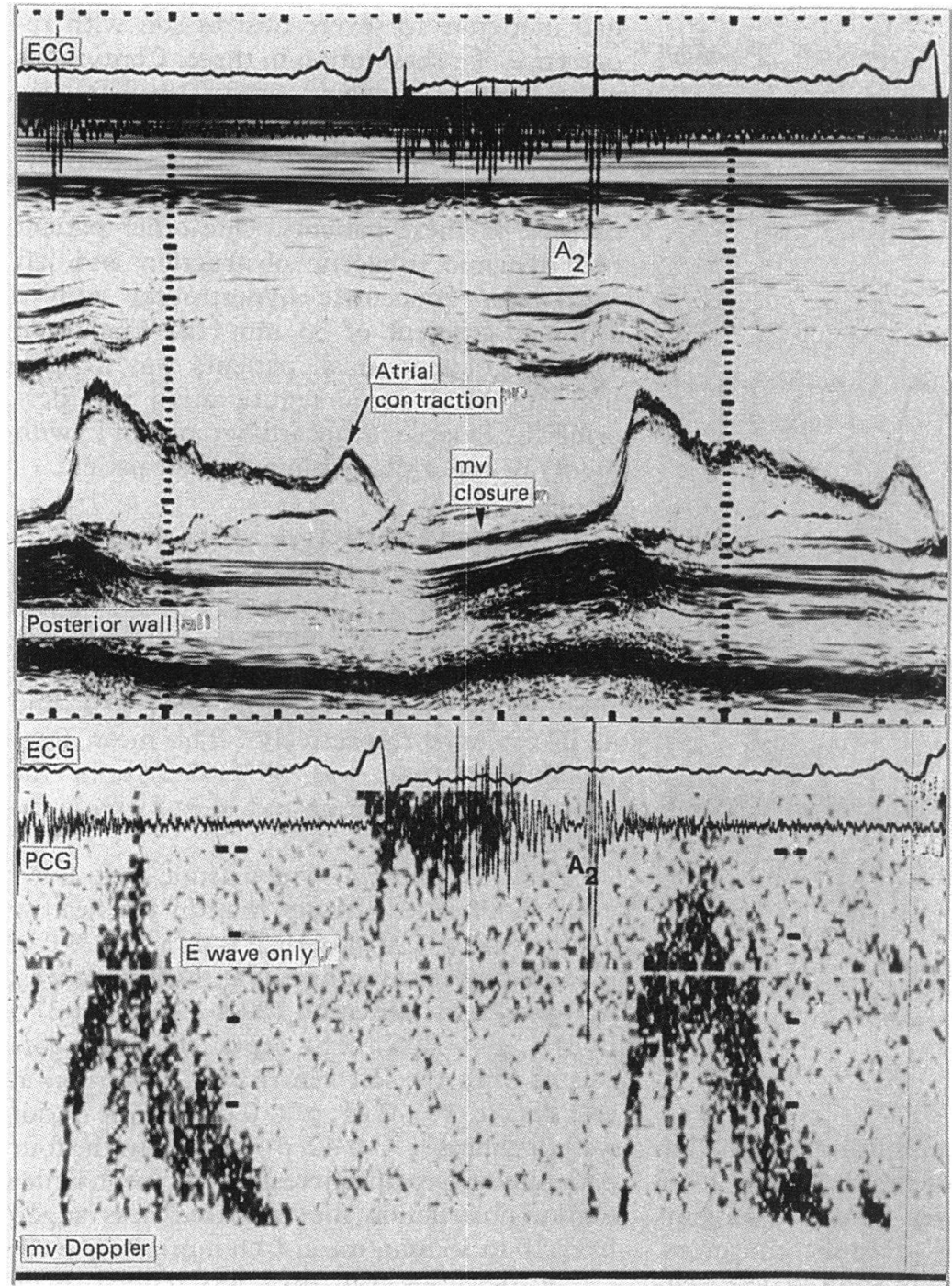

Figure 2 (Top) M mode echocardiogram taken through the level of mitral valve ( $m v$ ) leaflet tips. The mitral valve opens during atrial systole. (Bottom) Transmitral flow velocity recording from the same patient showing no significant forward flow during atrial systole. ECG, electrocardiogram; PCG, phonocardiogram.

gesting the presence of mechanical atrial activity in late diastole but the inability of the left ventricle to be effectively filled during this phase of the cardiac cycle.

\section{DIASTOLIC TIME INTERVALS}

There was no difference in $R / R$ interval between patients and controls $(p=0.48)$. Three patients had zero left ventricular isovolumic relaxation time from mitral valve Doppler flow velocity and four from mitral valve $M$ mode recordings, two of whom had residual left ventricular outflow obstruction (fig 3). The remaining patients had an isovolumic relaxation time of $46.7(15.0) \mathrm{ms}$ from Doppler velocities and $28.2(12.5) \mathrm{ms}$ from $M$ mode echocardiography. These were significantly shorter than those obtained in the healthy controls $(59.3(8.77) \mathrm{ms}(\mathrm{p}=0.01)$ and 45.91 $(7.81) \mathrm{ms}(\mathrm{p}=0.0001)$ respectively). The interval between $A_{2}$ to early diastolic peak Doppler velocity $(111.2 \quad(26.9) \quad v \quad 139.6$ $(16 \cdot 1) \mathrm{ms}, \mathrm{p}=0.005)$ was also shorter, and the E wave deceleration time (118.6 (14.5) $v 145.4$ $(25 \cdot 2) \mathrm{ms}, \mathrm{p}=0.005)$ was significantly reduced with no difference in the acceleration time $(75 \cdot 6$ $(11.8) v 83.1$ (13.3) $\mathrm{ms}, \mathrm{p}=\mathrm{NS}$ ). There were no relations between any indices measured and either age at surgery or time since surgery. Linear regression analysis (least squares) did not show any significant correlation between the degree of left ventricular hypertrophy and any of the indices of diastolic function.

\section{Discussion}

Fixed subaortic stenosis caused by a thin discrete fibrous shelf or a thick fibrous ring is present in a considerable proportion of patients with left ventricular outflow tract obstruction. Our study group is similar to others ${ }^{819-21}$ in terms of preoperative severity and the $50 \%$ incidence of associated anomalies including ventricular septal defects, coarctation of the aorta, and mitral valve abnormalities. Fixed subaortic stenosis is usually progressive and most patients will require surgery. In the absence of associated severe mitral stenosis, the operative mortality or morbidity is $l o w^{1}$ and prolonged survival can be expected, most patients having good relief of the obstruction in the short term. ${ }^{582}$ However, the operation may

Figure 3 Transmitral flow velocity recorded in patient with moderate restenosis. The left ventricular isovolumic relaxation time is zero. mvo, mitral valve opening, ECG, electrocardiogram; $P C G$, phonocardiogram.

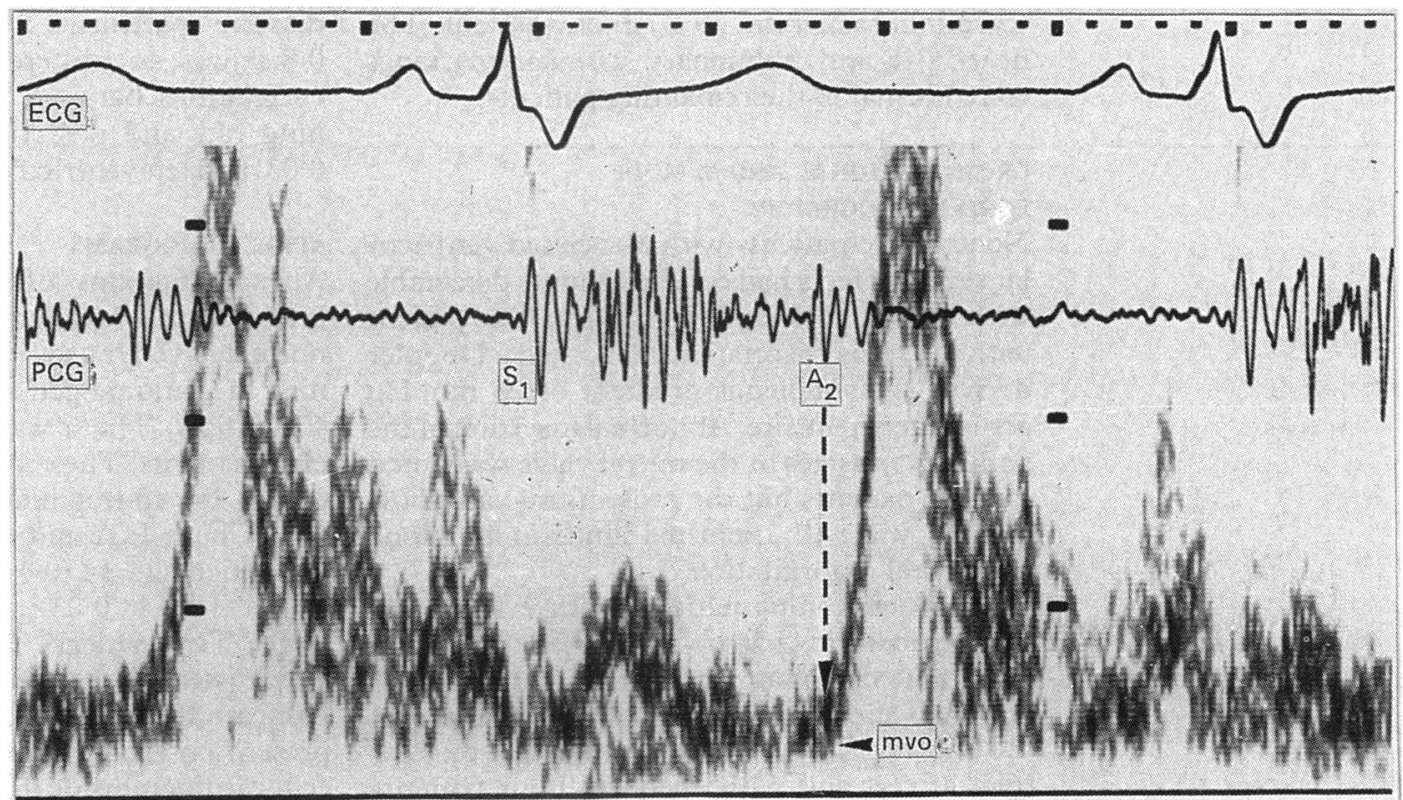


not be curative because of problems with residual or recurrent obstruction and aortic regurgitation in some patients..$^{2-468}$ Indeed, in our study more than half of the patients had residual left ventricular outflow obstruction of varying degrees and 14 patients had mild aortic regurgitation.

Left ventricular function was often abnormal. The septum was significantly thickened and the posterior wall showed the same tendency; mean percentage systolic thickening of the septum and posterior wall, however, were normal. The size of the left ventricular cavity at end diastole and end systole and thus fractional shortening were also normal, showing that systolic function was well preserved.

In contrast with this, diastolic left ventricular function was appreciably abnormal. The normalised peak rate of posterior wall thinning was significantly reduced as was the isovolumic relaxation time (it was $0 \mathrm{~ms}$ in four patients). The increase in mitral valve flow velocity in early diastole shown by Doppler inflow measurements was larger than that caused by atrial contraction in late diastole (higher $\mathrm{E}$ $\mathrm{E}+\mathrm{A}$ ratio). In some patients, there was complete absence of ' $A$ ' wave flow despite there being obvious ' $a$ ' waves on the apexcardiogram and $M$ mode echocardiogram. The apexcardiograms provided further evidence of impaired diastolic function, with half of them suggesting raised end diastolic pressures. The E wave deceleration time was also significantly reduced. This type of abnormality occurs when there is a large increase in pressure per unit volume during the early diastolic filling phase, ${ }^{23} 24$ indicating a restrictive left ventricular filling pattern.

The characteristic pattern of diastolic dysfunction we saw in our patients differs significantly from that described in adults and children with hypertrophy caused by valvar aortic stenosis, ${ }^{2526}$ hypertrophic cardiomyopathy, and pressure overload hypertrophy. ${ }^{2728}$ In all previous studies of patients with these diseases, systolic function was preserved, but isovolumic relaxation time was prolonged and wall motion incoordinate as shown by a reduced rate of dimension increase and decreased thinning rate, a lower ' $E$ ' velocity with a higher ' $A$ ' velocity and a longer deceleration time. Our results showed a quite different pattern of diastolic dynamics, which simulated a restrictive myocardial process. The isovolumic relaxation time was shorter with an increased ' $E$ ' and a small or absent ' $A$ ' and a reduced deceleration time though the thinning rate was reduced. The presence of an ' $a$ ' wave on the apexcardiogram and the absence of effective filling on Doppler flow during atrial contraction strongly suggest that end diastolic compliance is very low. The mechanisms underlying these differences are not certain.

The impact of residual problems in postsurgical subaortic stenosis may not be appreciated from a clinical examination, electrocardiogram, or resting left ventricularaortic gradient. Most of our patients were symptom free. Our study, however, showed significant alterations in the diastolic function of the left ventricle consistent with a stiff myocardium with reduced compliance and restricted filling. Patients therefore need careful supervision, regular follow up, and postoperative haemodynamic evaluation by various means to identify those with late unsatisfactory results and to provide remedial measures as far as possible.

We thank Dr E A Shinebourne, Dr J S Carvalho, and our surgical colleagues for their assistance.

1 Somerville J. Fixed subaortic stenosis-a frequently misunderstood lesion. Editorial note. Int J Cardiol 1985, 8:145-8.

2 Bjorn-Hansen LS, Lund O, Nielson TT, Kromann-Hansen $\mathrm{O}$, Jensen FT. Aortic regurgitation after surgical relief of subvalvular membranous stenosis: a long-term follow-up study. Scand J Thorac Cardiovasc Surg 1988;22:275-80.

3 Binet JP, Lasay J, Demontoux S, Planche C, Langlois J. Subvalvular aortic stenosis: long-term surgical results. Thorac Cardiovasc Surg 1983;31:96-100.

4 Moses RD, Barnhart GR, Jones M. The late prognosis after localised resection of fixed (discrete and tunnel) left ventricular outflow tract obstruction. J Thorac Cardiovasc ventricular outflow tract

5 Champsaur G, Trusler GA, Mustard WT. Congenital discrete subvalvar aortic stenosis: surgical experience and long-term follow-up in 20 paediatric patients. $\mathrm{Br}$ Heart $\mathrm{J}$ 1973;35:443-6.

6 Hardesty RL, Griffith BP, Mathews RA, et al. Discrete subvalvular aortic stenosis: an evaluation of operative therapy. J Thorac Cardiovasc Surg 1977;74:352-61.

7 Freedom RM, Pelech A, Brand A, et al. The progressive nature of subaortic stenosis in congenital heart disease. Int $J$ Cardiol 1985;8:137-43.

8 Somerville J, Stone S, Ross D. Fate of patients with fixed subaortic stenosis after surgical removal. Br Heart $J 1980$; 43:629-47.

9 Newton A, Desser KB, Benchimol A. Apexcardiogram in the assessment of left ventricular function. Adv Cardiol the assessment

10 Craigie E, Damon S. Heart sounds: phonocardiography, carotid, apex and jugular venous pulse tracings; and systolic time intervals. In: Braunwald E, ed. Heart disease-textbook of cardiovascular medicine. Philadelphia: WB Saunders, 1980:41-63.

11 Voigt GC, Friesinger GC. The use of apexcardiography in the assessment of left ventricular diastolic pressure. Circulation 1970;41:1015-23.

12 Dawson R. Digitised M-mode echocardiograms. In: St John Sutton M, Oldershaw P, eds. Textbook of adult and paediatric echocardiography and Doppler. Boston: Blackwell Scientific Publications, 1989:137-53.

13 Upton MT, Gibson DG. The study of left ventricular function from digitised echocardiograms. Prog Cardiovasc Dis 1978;20(No 5):359-84.

14 Gibson DG, Brown D. Measurement of instantaneous left ventricular dimension and filling rate in man, using ventricular dimension and filling rate in man,

15 Mirsky I. Assessment of diastolic function: suggested methods and future considerations. Circulation 1984; 69:836-41.

16 Little WC, Downes TR. Clinical evaluation of left ventricular diastolic performance. Prog Cardiovasc Dis 1990; 32(No 4):273-90.

17 Nishimura RA, Abel MD, Hatle LK, Tajik AJ. Assessment of diastolic function of the heart: background and current applications of Doppler echocardiography. Part II. Clinical studies. Mayo Clin Proc 1989;64:181-204.

18 Labovitz AJ, Pearson AC. Evaluation of left ventricular diastolic function: clinical relevance and recent Doppler: chocardiographic insights. Am Heart J 1987;114:836-49.

19 Schneeweiss A, Motro M, Shem-Tov A, Bleiden LC, Neufield HN. Discrete subaortic stenosis associated with congenital valvular aortic stenosis-a diagnostic challenge. Am Heart J 1982;106:55-9.

20 Vogel M, Freedom RM, Brand A, Trusler GA, Williams WG, Rowe RD. Ventricular septal defect and subaortic stenosis: an analysis of 41 patients. Am J Cardiol 1983;52: 1258-63.

21 Chung KJ, Fulton DR, Kriedberg MB, Payne DD, Cleveland RJ. Combined discrete subaortic stenosis and
ventricular septal defect in infants and children. Am J ventricular septal defect

22 Edwards H, Mulder DG. Surgical management of subaortic stenosis. Arch Surg 1983;118:79-83.

23 Appleton CP, Hatle LK, Popp RL. Demonstration of restrictive ventricular physiology by Doppler echocardiography. J Am Coll Cardiol 1988;11:757-68.

24 Appleton CP, Hatle LK, Popp RL. Relation of transmitral flow velocity patterns to left ventricular diastolic function. New insights from a combined hemodynamic and Doppler echocardiographic study. J Am Coll Cardiol 1988;12:426-40.

25 Fifer MA, Borow KM, Colan SD, Lorell BH. Early diastolic eft ventricular function in children and adults with aortic stenosis. J Am Coll Cardiol 1985;5:1147-54.

26 Friedman MJ, Sahn DJ, Burris HA, Allen HD, Goldberg SJ. Computerised echocardiographic analysis to detect abnormal systolic and diastolic left ventricular function in children with aortic stenosis. Am J Cardiol 1979;44: 478-86.

27 Gibson DG, Traill TA, Hall RJC, Brown DJ. Echocardiographic features of secondary left ventricular hypergraphic features of secondary.

28 Sanderson JE, Traill TA, St John Sutton MG, Brown DJ, Gibson DG, Goodwin JF. Left ventricular relaxation and filling in hypertrophic cardiomyopathy: an echocardiofilling in hypertrophic cardiomyopathy: an
graphic study. Br Heart J 1978;40:596-601. 